OPEN ACCESS

Edited by:

Jian Du,

Anhui Medical University, China

Reviewed by:

Rui Zhou,

Wuhan University, China

Jan Mead

Emory University, United States

${ }^{*}$ Correspondence:

Amir Kol

akol@ucdavis.edu

Specialty section:

This article was submitted to

Parasite and Host,

a section of the journal

Frontiers in Cellular

and Infection Microbiology

Received: 31 March 2021

Accepted: 07 May 2021

Published: 25 May 2021

Citation:

Crawford CK and Kol A (2021) The

Mucosal Innate Immune Response

to Cryptosporidium parvum,

a Global One Health Issue.

Front. Cell. Infect. Microbiol. 11:689401.

doi: 10.3389/fcimb.2021.689401

\section{The Mucosal Innate Immune Response to Cryptosporidium parvum, a Global One Health Issue}

\author{
Charles K. Crawford and Amir Kol *
}

Department of Pathology, Microbiology, \& Immunology, School of Veterinary Medicine, University of California, Davis, Davis, CA, United States

Cryptosporidium parvum is an apicomplexan parasite that infects the intestinal epithelium of humans and livestock animals worldwide. Cryptosporidiosis is a leading cause of diarrheal-related deaths in young children and a major cause of economic loss in cattle operations. The disease is especially dangerous to infants and immunocompromised individuals, for which there is no effective treatment or vaccination. As human-to-human, animal-to-animal and animal-to-human transmission play a role in cryptosporidiosis disease ecology, a holistic 'One Health' approach is required for disease control. Upon infection, the host's innate immune response restricts parasite growth and initiates the adaptive immune response, which is necessary for parasite clearance and recovery. The innate immune response involves a complex communicative interplay between epithelial and specialized innate immune cells. Traditional models have been used to study innate immune responses to $C$. parvum but cannot fully recapitulate natural host-pathogen interactions. Recent shifts to human and bovine organoid cultures are enabling deeper understanding of host-specific innate immunity response to infection. This review examines recent advances and highlights research gaps in our understanding of the host-specific innate immune response to C. parvum. Furthermore, we discuss evolving research models used in the field and potential developments on the horizon.

Keywords: Cryptosporidium parvum, innate immune response, One Health, intestinal parasite, intestinal epithelium

\section{INTRODUCTION}

Cryptosporidium parvum is an apicomplexan parasite that causes potentially life-threatening infectious diarrhea in infants and neonate calves with no available FDA-approved vaccine (Abrahamsen et al., 2004; Abubakar et al., 2007). Nitazoxanide is approved for use in adult, immunocompetent patients, but is not effective or approved for use in the most vulnerable populations: infants and immunocompromised patients (Abubakar et al., 2007). Infected hosts (humans and cows) shed billions of highly infectious and environmentally stable parasites (Nydam et al., 2001; Zambriski et al., 2013). The parasite is transmitted zoonotically and between humans worldwide (Bouzid et al., 2013; Ryan et al., 2016; Hatam-Nahavandi et al., 2019), and it contaminates drinking water sources (Chique et al., 2020), recreational swimming sites ( $\mathrm{Li}$ et al., 2019), soils (Nag et al., 2020), and aquaculture environments (Marquis et al., 2015). Wildlife is further impacted by cryptosporidiosis (Ziegler et al., 2007). As such, a comprehensive and 
interdisciplinary research approach is required to eliminate this significant source of global disease burden. Cryptosporidiosis is one of three etiologies responsible for the most global diarrheal deaths in children younger than five years of age (Checkley et al., 1997; Ong et al., 2005; Gormley et al., 2011; Kotloff et al., 2013; Khalil et al., 2018). In the U.S. C. parvum caused the largest waterborne pathogen outbreak in American history (Corso et al., 2003), and 444 outbreaks of cryptosporidiosis were reported from 2009-2017, leading to an estimated 750,000 individual cases per year (Scallan et al., 2011; Gharpure et al., 2019). Cryptosporidium has even been included as a relevant biological threat agent by the CDC (Rotz et al., 2002).

While the role of $\mathrm{CD}^{+} \mathrm{T}$ cells in clearing infection is well studied, the role of the innate immune response within the parasite's natural hosts (i.e. human and cattle) is not fully understood. We will succinctly review current advances in our understanding of the mucosal innate immune response to C. parvum, and innovative models that have the potential to elucidate such responses within clinically relevant hosts. We will highlight key knowledge gaps and future research opportunities.

\section{INNATE IMMUNE RESPONSE}

The intestinal innate immune system, comprised of the gut epithelium and specialized innate immune cells, is the first line of defense against C. parvum infection. Innate immunity restricts the expansion and growth of the parasite and initiates the adaptive response. Understanding the innate immune response to C. parvum infection in its native hosts is critical in building a 'One Health' strategy to limit Cryptosporidium's devastating impact on global health, agriculture, and the environment (Ziegler et al., 2007; Laurent and Lacroix-Lamande, 2017; Ivanova et al., 2019).

\section{Intestinal Epithelial Cells}

Intestinal epithelial cells that line the gut epithelium create a physical barrier between luminal content and internal tissues.

Because C. parvum infects intestinal epithelial cells and does not invade deeper tissues, the epithelium is particularly important regarding the immune response to C. parvum.

Primary bovine intestinal epithelial cell infection by C. parvum leads to activation of the inflammatory transcription factor NF- $\mathrm{BB}$; this increases expression of the long noncoding RNA NR_045064 (Li et al., 2018) and induces the transcription of numerous inflammatory mediators, primarily CXCL8 (aka IL-8) and TNF $\alpha$, a response primarily mediated by Toll-like receptor-2 (TLR2) and TLR4 (Yang et al., 2015). C. parvum infection induces an increase in TLR4 expression, regulated by suppression of the noncoding miRNA, let-7i (Chen et al., 2007). TLR2 and TLR4 activation by C. parvum and subsequent NF- $\kappa \mathrm{B}$ nuclear translocation induces the release of antimicrobial peptides LL-37 and $\beta$-defensin-2 (Chen et al., 2005). Despite this, TLR2 and TLR4 deficiency did not increase parasite load in neonatal mice; however, direct comparisons are difficult given the different models and experimental designs (Lantier et al., 2014).
Evidence suggests that intracellular recognition of C. parvum via NOD-like receptors (NLR) and subsequent activation of the inflammasome complex is an important innate response to infection. IL-18, a product of the inflammasome complex, is elevated in human epithelial cell lines following C. parvum infection (McDonald et al., 2006); moreover, IL-18 knockout and inflammasome components caspase-1 or ASC knockout mice are more susceptible to Cryptosporidium infection than control mice (Ehigiator et al., 2005; McNair et al., 2018; Sateriale et al., 2021). IL-1 $\beta$, the second key product of inflammasome activation, was not increased post-infection, nor was there an effect on infection susceptibility in IL-1 $\beta$ knockout mice (McNair et al., 2018). The latter findings are corroborated by the fact that parasite shedding was strongly increased in mice lacking NLRP6, which induces IL-18 secretion, but not in mice lacking other inflammasome-forming NLRs including NLRP3, NLRP1b, Aim2, and NLRc4 that primarily induce IL-1 $\beta$ secretion (Sateriale et al., 2021).

Antimicrobial peptides include small positively-charged polypeptides that elicit antimicrobial effects against a variety of pathogens including bacteria, fungi, viruses, and protozoan parasites (Mahlapuu et al., 2016). Phospholipases (Carryn et al., 2012) and the antimicrobial peptides $\beta$-defensin-1, $\beta$ defensin-2, and LL-37 can kill C. parvum (Giacometti et al., 1999). Part of the TLR signal response by epithelial cells includes the release of LL-37 and $\beta$-defensin-2, and these antimicrobial peptides bind to free $C$. parvum to directly enact their effects (Chen et al., 2005). LL-37 and $\alpha$-defensin- 2 are increased in response to the rise in the inflammasome product, IL-18, in human cell lines (McDonald et al., 2006). However, C. parvum influences epithelial cells by inhibiting the production of other antimicrobial peptides including $\beta$-defensin- 1 by an undiscovered mechanism (Zaalouk et al., 2004), and CCL20 by a C. parvum-induced rise in miR21 (Guesdon et al., 2015).

C. parvum infection is restricted to a parasitophorous vacuole on the apical side of the intestinal epithelium, therefore chemokine and cytokine release from infected epithelial cells is critical in the recruitment of specialized immune cells that facilitate parasite clearance (Laurent et al., 1999). Activation of TLRs by $C$. parvum induces the NF- $\mathrm{KB}$ signaling pathway causing the basolateral release of Growth Regulated Oncogene$\alpha$ (GRO- $\alpha$ ) (Yang et al., 2015) and CXCL8, which are key neutrophil chemoattractant molecules (Laurent et al., 1997). Additionally, in the neonatal mouse model, several chemokines including CCL2, CCL5, CXCL10, and CXCL9 are released, which recruit various immune cells to the infection site (LacroixLamande et al., 2002; Auray et al., 2007; Lantier et al., 2013). Chemokine-induced immune cell recruitment is critical in the response to $C$. parvum, as evidenced by the increased susceptibility to infection of mice deficient in chemokine receptors, even in spite of redundancy in immune cell recruitment processes (Lacroix-Lamande et al., 2008; Lantier et al., 2013).

Another defense against intracellular pathogens is apoptosis of the host cell, and infection by C. parvum initiates apoptosis of infected and surrounding epithelial cells through Fas and Fas-L 
interactions (Chen et al., 1999). However, within hours postinfection, C. parvum in one life stage, the trophozoite, inhibits apoptosis, likely to facilitate growth within the host cell, by inducing the production of anti-apoptotic factors BCL-2 (Mele et al., 2004), survivin (Liu et al., 2009), and osteoprotegerin (McCole et al., 2000; Castellanos-Gonzalez et al., 2008). Later in infection, in a different part of the C. parvum life cycle known as the sporozoite and merozoite life stages, inhibition is removed and apoptosis of the host cell is promoted (Mele et al., 2004; Liu et al., 2009).

\section{Interferons (IFNs)}

IFNs are an essential component to the host response to $C$. parvum. The importance of IFN- $\boldsymbol{\gamma}$ is shown by an increased susceptibility to C. parvum infection in IFN- $\gamma^{-1-}$ mice (Mead and You, 1998; Lacroix-Lamande et al., 2002) and wild-type neonate mice treated with anti-IFN- $\gamma$-antibodies (McDonald et al., 2013). Adult mice with a disrupted IFN- $\gamma$ gene shed more parasites, experience extensive damage to the intestinal mucosa, and die within weeks of infection (Theodos et al., 1997). Severe combined immunodeficiency (SCID) mice, which are deficient in $\mathrm{T}$ and $\mathrm{B}$ cells, experience reduced C. parvum infection compared to SCID IFN- $\gamma^{-/-}$mice, showing that protective IFN$\gamma$ during C. parvum infection is derived, at least in part, from non-T or B cells (Hayward et al., 2000). In addition to increased IFN- $\gamma$, in vivo piglet infection and in vitro experiments show that intestinal epithelial cells secrete abundant IFN- $\lambda \mathbf{3}$ (a type-III IFN) independently of specialized immune cells (Ferguson et al., 2019). Historically, type III IFNs have been associated with local epithelial defense from viruses (Zhou et al., 2018). More recently, IFN- $\lambda$ was shown to mediate the gut epithelium defense against non-viral pathogens via TLRs (Odendall et al., 2017). Neutralization of IFN- $\lambda 3$ leads to increased villus blunting and fecal shedding of infective C. parvum in neonate mice, and when intestinal epithelial cells are primed with recombinant IFN- $\lambda 3$ they show reduced barrier disruption and increased cellular defense against C. parvum (Ferguson et al., 2019).

\section{Specialized Immune Cells Natural Killer (NK) Cells}

NK cells contribute to the innate immune response to C. parvum through IFN- $\gamma$ production and cytolysis of infected epithelial cells. In vivo, treating immunocompetent or immunodeficient mice with the NK cell activator, IL-12, leads to a protective effect against C. parvum associated with a concomitant rise in intestinal IFN- $\gamma$ (Urban et al., 1996); in vitro, human NK cells lyse infected intestinal epithelial cells in response to IL-15 and presentation of MHC class I-related protein A and B (Dann et al., 2005). Mice lacking NK cells experience increased severity of infection and excrete more oocysts compared to mice with NK cells, but when treated with anti-IFN- $\gamma$ antibodies the infection of NK positive mice was heavily exacerbated, thus implying a protective role of NK cells that is connected to IFN- $\gamma$ (Barakat et al., 2009). Despite the increased morbidity in mice without NK cells, they produced IFN- $\gamma$ after infection, meaning that NK cells are one, but not the only source of IFN- $\gamma$ in response to $C$. parvum. The number of NK cells localized in the gut is increased within days following C. parvum exposure in lambs (Olsen et al., 2015). Activation of the NK cell receptor, NKG2D, is involved in NK cell-mediated protection, via its ligand, MICA, which is upregulated in the intestinal epithelium of infected humans (Dann et al., 2005). The role that other innate-like lymphocytes play during C. parvum infection is poorly understood and future investigations are warranted.

\section{Dendritic Cells (DCs)}

DCs exposed to C. parvum secrete numerous cytokines including IL-6, IL-1 $\beta$, IL-12, IL-18, TNF $\alpha$, and type I interferons via TLR4 receptor activation (Barakat et al., 2009; Bedi and Mead, 2012; Perez-Cordon et al., 2014). DCs also capture C. parvum antigens in the gut mucosa and migrate to draining lymph nodes where they present these antigens and facilitate the adaptive immune response (Auray et al., 2007; Perez-Cordon et al., 2014). DCs may acquire such antigens by directly capturing luminal organisms or phagocytizing apoptotic infected epithelial cells (Farache et al., 2013). Macrophages may further engulf free $C$. parvum and transfer the parasite to DCs for migration (Marcial and Madara, 1986). One hypothesis for the increased infection susceptibility of neonatal mice compared to adults is that neonates have fewer intestinal DCs, and injecting neonates with Flt3L - which induces DC differentiation from progenitor cells - increases the number of DCs as well as resistance to infection (Lantier et al., 2013). Furthermore, adult mice devoid of DCs are more susceptible to infection and excrete more parasites, and adoptive transfer of DCs pre-exposed to C. parvum reduces the parasite load (Bedi et al., 2014).

\section{Macrophages}

Macrophages develop from the same bone marrow precursor cells as DCs and are found in most organ systems and epithelial barriers, including the gut (Verschoor et al., 2012; Kumar, 2019). Following C. parvum infection in neonatal mice, macrophages accumulate in the lamina propria (de Sablet et al., 2016) and are associated with intact and digested parasites in Payer's patches in guinea pigs (Marcial and Madara, 1986). Macrophages' contribution to $C$. parvum clearance appears to be primarily as a secondary source of IFN- $\gamma$. Infected Rag $2^{-/-} \gamma_{c}^{-/-}$mice, which lack $\mathrm{T}$ and $\mathrm{B}$ lymphocytes and NK cells, still produce IFN- $\gamma$, suggesting an IFN- $\gamma$ source alternative to T cells and NK cells (Barakat et al., 2009). When treated with clodronate-liposomes to deplete macrophages, the mice were less resistant to C. parvum and could not produce IFN- $\gamma$ (Barakat et al., 2009). IFN- $\gamma$ production by macrophages is promoted by IL-18 when $\operatorname{Rag}^{-/-} \gamma_{c}^{-/-}$mice are infected by C. parvum (Choudhry et al., 2012), and IFN- $\gamma^{-1-}$ mice have fewer macrophages and $\mathrm{T}$ cells recruited to the gut accompanying an inability to recover from infection (Lacroix-Lamande et al., 2002).

\section{Neutrophils}

Neutrophils infiltrate the intestinal mucosa during C. parvum infection (Goodgame et al., 1995), and preventing mucosal recruitment of neutrophils increases C. parvum-related barrier 
dysfunction as measured by transepithelial electrical resistance (Zadrozny et al., 2006). Inhibiting neutrophil recruitment does not influence mortality or infection severity, nor does it affect $C$. parvum-mediated villous atrophy and diarrhea (Zadrozny et al., 2006). With no influence on mortality or infection severity, it does not appear that neutrophils are directly protective in the context of C. parvum.

As research models advance, the multi-dimensional innate immune response grows more complex but better understood (Figure 1). However, questions regarding the relevancy of these data to the natural hosts of $C$. parvum remain, provided the use of models that do not fully recapitulate the environment of human or ruminant intestines. New biotechnological advances, such as the development of bovine and human organoids, may provide the models necessary to confirm what is currently inferred about the innate immune response to $C$. parvum in these hosts.

\section{CRYPTOSPORIDIUM RESEARCH MODELS}

The potential to fully understand C. parvum's pathogenesis and develop therapeutics is dependent on the models used to research the host-pathogen interactions it induces within its natural and clinically relevant hosts (i.e. human and cattle). Traditional in vitro $C$. parvum infection models can only be maintained for several days at a time and do not fully recapitulate native intestinal tissue, and In vivo mouse models are sub-optimal, as mice are not a natural host of C. parvum. Innovative models and advancing technologies are necessary to advance this field.

\section{In Vivo Models}

In vivo animal models are foundational to host-pathogen interaction research, but the nature of $C$. parvum complicates the application of traditional animal models. The natural and clinically

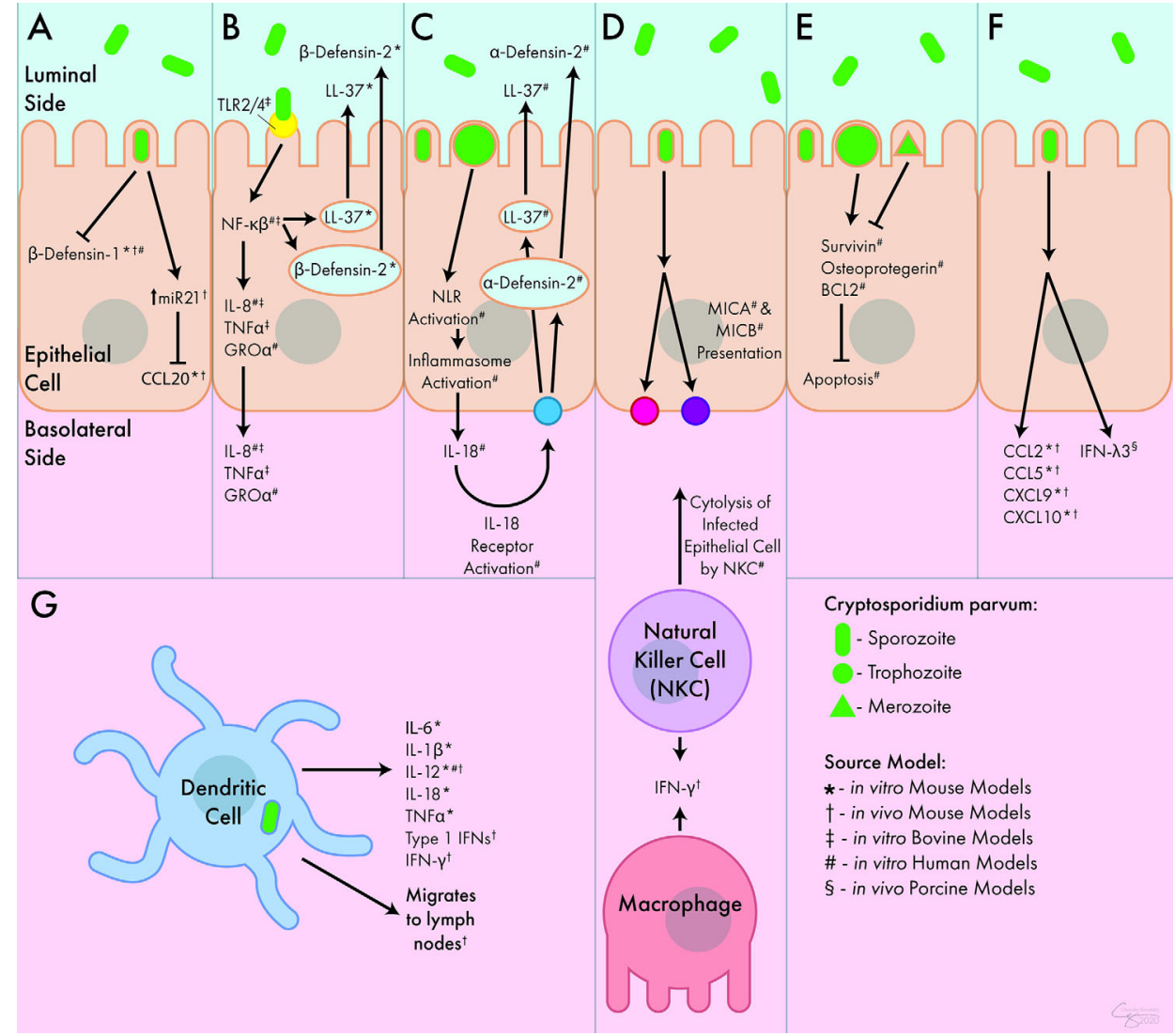

FIGURE 1 | Innate Immune Response to C. parvum. (A) C. parvum inhibits the release of the antimicrobial peptides $\beta$-defensin-1 and CCL20. (B) Activation of TLR receptors by $C$. parvum leads to the luminal secretion of antimicrobial peptides $\beta$-defensin- 2 and LL- 37 as well as the basolateral secretion of IL- 8 , TNF $\alpha$, and GRO $\alpha$. (C) Inflammasome activation by C. parvum leads to the basolateral release of IL-18, which causes the luminal secretion of $\alpha$-defensin-2 and LL-37. (D) C. parvum-mediated presentation of MICA and MICB lead to cytolysis of infected epithelial cells by NK cells. NK cells and macrophages both act as sources of IFN- $\gamma$ during infection. (E) C. parvum trophozoites stimulate apoptosis, but merozoites inhibit apoptosis, mediated through survivin, osteoprotegerin, and BCL2. (F) In response to $C$. parvum, intestinal epithelial cells release numerous chemokines and cytokines including CCL2, CCL5, CXCL9, CXCL10, and IFN- $\lambda 3$.

(G) DCs respond to C. parvum by releasing IL-6, IL-1 $\beta, I L-12, I L-18, T N F \alpha$, and type I interferons. They can also migrate to lymph nodes following parasite exposure. Interferon (IFN), Interleukin (IL-), Tumor Necrosis Factor (TNF), C-C Chemokine Ligand (CCL), C-X-C Chemokine Ligand (CXCL), Growth Regulated Oncogene (GRO), Toll-Like Receptor (TLR), Nod-Like Receptor (NLR), MicroRNA 21 (miR21), Nuclear Factor (NF), Cathelicidin (LL-37), Major Histocompatibility Complex Class I Chain-Related Protein (MIC), B-Cell Lymphoma 2-Apoptosis Regulator (BCL2), Natural Killer Cell (NKC). 
relevant hosts for C. parvum are humans and ruminants; mice can sustain C. parvum infection but only when severely immunocompromised (Mead et al., 1991; Petry et al., 1995; Griffiths et al., 1998). Given that humans and ruminants are the primary natural hosts, calves, lambs, and non-human primates have been used to investigate cryptosporidiosis in naturally infected species (Tzipori, 1998). However, housing and maintaining large animal species requires significant funds and specialized facilities, equipment, and training. Moreover, many of the genetic and molecular research tools that are available for mice models are not available for large animal models such as cows or sheep.

Adult mice, a preferred animal model in terms of costs and availably of reagents, are resistant to $C$. parvum but are susceptible to infection by the related species, C. muris; however, C. muris differs from C. parvum in phylogeny, biochemical nature of infection, and infection site (C. muris infects the stomach mucosa) (Sateriale et al., 2019). Mice can become susceptible to C. parvum through chemical or genetic immunosuppression, such as the previously discussed SCID (Mead et al., 1991), IFN- $\gamma^{-/-}$(Griffiths et al., 1998), and Rag2 $2^{-/-}$ mice, which, in addition to neonate mice, have provided established murine platforms for C. parvum research (Petry et al., 1995). Unfortunately, mouse models have limited translatability for natural hosts such as humans and cattle. This has been elucidated through bovine-specific responses to C. parvum that are absent in mice, such as differences in NK cell receptor activation (Allan et al., 2015), recruitment of $\gamma \delta$ T cells (Guzman et al., 2012), and developed resistance in adulthood (Sateriale et al., 2019). More recently, C. tyzzeri was identified as a natural mouse pathogen that mirrors aspects of C. parvum's pathogenesis and host response in mice (Sateriale et al., 2019).

\section{In Vitro Models}

The allure of primary intestinal epithelium cells lies in the morphological and species-specific accuracy compared to immortalized cell lines. Primary human (Castellanos-Gonzalez et al., 2013) and bovine intestinal epithelial cells have been successfully infected with C. parvum (Hashim et al., 2006). Unfortunately, primary intestinal cells have limitations involving their availability, obsoletion, and difficulty in longterm propagation (Varughese et al., 2014).

Most in vitro models for C. parvum host-pathogen interaction research include cancer-derived transformed or immortalized human cell lines including HCT-8, Caco-2, and HT29 cells, which are all derived from colorectal adenocarcinomas (Karanis and Aldeyarbi, 2011). Other non-colorectal cancer cell lines have also been used: RL95-2 (human endometrial carcinoma) (Rasmussen et al., 1993), Madin-Darby bovine kidney cells (Upton et al., 1994), MRC-5 (lung fibroblast) (Dawson et al., 2004), FHs 74 Int cells (non-cancer, immortalized human small intestinal epithelium) (Varughese et al., 2014), and BS-C-1 (African green monkey kidney) cells (Deng and Cliver, 1998). None of these lines maintained infection longer than six days except for HT29 cells, which could maintain infection for thirteen days but only for the asexual life stages of C. parvum. One non-intestinal cell line, COLO-680N, is human esophageal squamous carcinoma-derived and can propagate infective parasites continually for eight weeks, but applications to hostpathogen interaction are questionable given that the esophagus is not the natural niche for C. parvum (Miller et al., 2018).

Early attempts to utilize three-dimensional structures for $C$. parvum research involved low-shear microgravity cultures where HCT-8 cells seeded onto submucosa grafts formed structures that maintained C. parvum infection; however, parasites decreased after 48 hours (Alcantara Warren et al., 2008). Later, a hollow fiber bioreactor system was used to infect threedimensional HCT-8 cell structures for over six months, which is far longer than two-dimensional HCT-8 infection, while producing significantly more oocysts/day/mL (Morada et al., 2016). Silk fiber scaffolding has also been utilized to induce threedimensional culture of Caco-2 and HT29 cells, maintaining infection for two weeks (DeCicco RePass et al., 2017).

While these cell lines are useful tools, they are susceptible to genetic variation, most cannot maintain all phases of the C. parvum life cycle, and most cannot maintain and propagate C. parvum infection for extended periods of time (Bhalchandra et al., 2018). This, in addition to the fact that these cell lines do not recapitulate the native intestinal epithelial tissue of C. parvum hosts, encourages the search for increasingly accurate models of study.

\section{Enteroids}

Intestinal organoids (aka enteroids) circumvent shortcomings exhibited by cell lines and primary epithelial cells while also introducing a three-dimensional culture model. Enteroids are composed of a polarized single layer of epithelium with crypt and villus domains containing the various intestinal epithelial cells such as stem cells, enterocytes, enteroendocrine cells, goblet cells, etc., thus recapitulating the microanatomy and functionality of native intestinal epithelial tissue (Figure 2) (Zachos et al., 2016).

Stem cell-derived organoids allow long-term threedimensional culture while maintaining the morphological relevance of native tissue. Isolated crypts from neonatal and immunocompromised mice were exposed to C. parvum upon plating, resulting in inhibited organoid propagation and budding, decreased expression of intestinal stem cell markers, and increased cell senescence (Zhang et al., 2016). In another study, human enteroids were infected with C. parvum by microinjection and the parasite was able to complete its entire life cycle within these organoids (Heo et al., 2018). Though bovine enteroids have been described, they have not yet been used to study C. parvum infection (Powell and Behnke, 2017; Hamilton et al., 2018; Derricott et al., 2019).

Organoid technology for C. parvum research is in its relative infancy, but the benefits of the culture model are enticing and allow questions that were not possible to investigate with previous models.

\section{DISCUSSION}

C. parvum is a parasite of international clinical importance across human and animal healthcare. Because of its high infectivity, resistance to water treatment, and the danger it poses to immunocompromised individuals, understanding the responses it induces in its host is a high priority endeavor to allow the creation of 

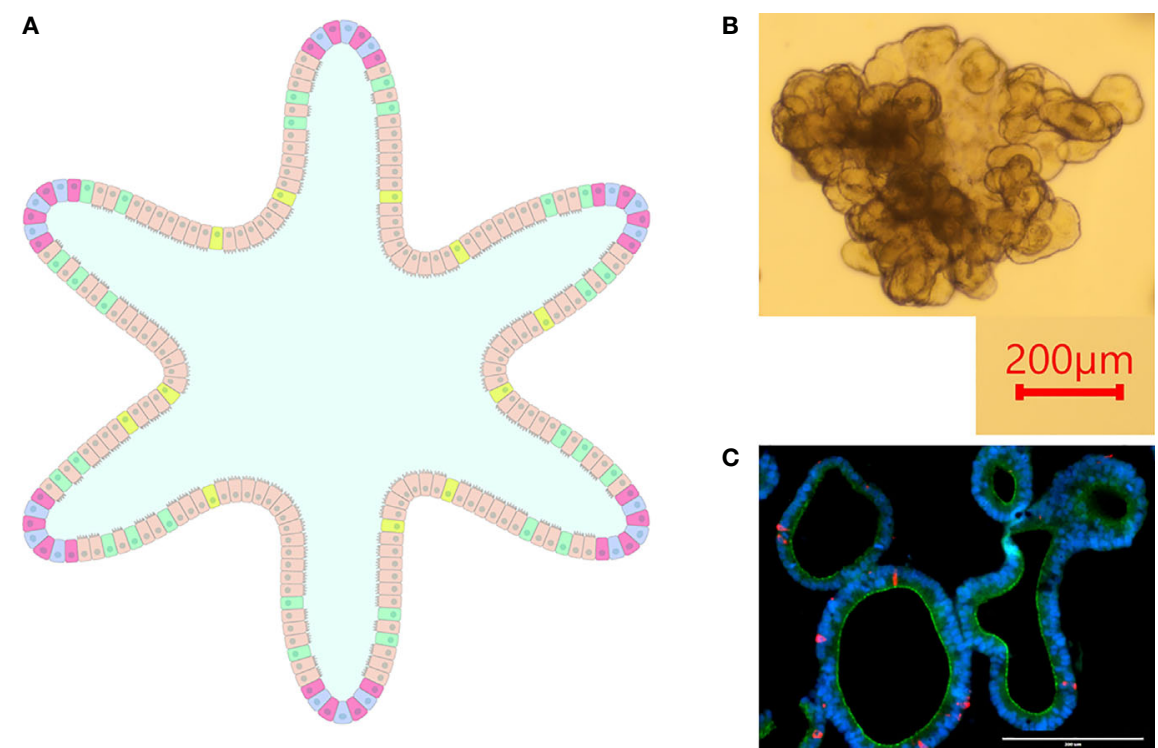

FIGURE 2 | Intestinal Organoids. (A) graphical representation of an intestinal organoid. The inside of the organoid corresponds to the luminal side, and the outside of the organoid corresponds to the basolateral side. Blue: intestinal stem cells, Red: Paneth cells, Tan: enterocytes, Green: goblet cells, Yellow: enteroendocrine cells. (B) Bovine intestinal organoid 6 days post-plating. Numerous folds and budding structures are noted, indicating crypt and villi-like domains. (C) Sectioned ovine intestinal organoid illustrating nuclei (DAPI), apical junctional protein ZO-1 (green), and chromogranin-A (red) indicating enteroendocrine cell differentiation.

effective preventative measures and therapies. The innate immune response is multifaceted and involves the intestinal epithelium, innate immune cells, and a complex interplay of cytokine signaling. To discover this, various models have been utilized. These include natural host species such as calves as well as more specialized models like immunocompromised mice, and in vitro models such as primary cell explants and immortalized cell lines. A relatively recent shift to three-dimensional cultures and the expanding use of organoids opens new avenues to study the parasite and its host-pathogen interaction.

As research in the field continues, attention must be brought to handling C. parvum from a 'One Health' perspective. New models must increase the relevant understanding of the parasite in bovine and human hosts and drive the discovery of innate mechanisms of resistance that can be utilized for management. Improved knowledge of the innate defenses against $C$. parvum in both ruminant and human hosts will hopefully lead to treatments to augment host natural innate defense and act as transient preventative measures to reduce environmental transmission of C. parvum between and within host species.

\section{REFERENCES}

Abrahamsen M. S., Templeton T. J., Enomoto S., Abrahante J. E., Zhu G., Lancto C. A., et al. (2004). Complete Genome Sequence of the Apicomplexan, Cryptosporidium Parvum. Science 304 (5669), 441-445. doi: 10.1126/science.1094786

Abubakar I., Aliyu S. H., Arumugam C., Hunter P. R., and Usman N. K. (2007). Prevention and Treatment of Cryptosporidiosis in Immunocompromised Patients. Cochrane Database Syst. Rev. 1 (1), CD004932. doi: 10.1002/14651858.CD004932.pub2

Alcantara Warren C., Destura R. V., Sevilleja J. E., Barroso L. F., Carvalho H., Barrett L. J., et al. (2008). Detection of Epithelial-Cell Injury, and Quantification of Infection,

\section{AUTHOR CONTRIBUTIONS}

CC performed writing - original draft preparation. CC and AK performed writing - review and editing. AK performed project administration and supervision. All authors contributed to the article and approved the submitted version.

\section{FUNDING}

The work presented here was supported by funding from The Center for Food and Animal Health of The National Institute of Food and Agriculture, grant number: CALV-RIVAS-0060.

\section{ACKNOWLEDGMENTS}

We thank Chrisoula Toupadakis Skouritakis, $\mathrm{PhD}$ for assistance in the development of Figures 1, 2.

in the HCT-8 Organoid Model of Cryptosporidiosis. J. Infect. Dis. 198 (1), 143-149. doi: $10.1086 / 588819$

Allan A. J., Sanderson N. D., Gubbins S., Ellis S. A., and Hammond J. A. (2015). Cattle NK Cell Heterogeneity and the Influence of MHC Class I. J. Immunol. 195 (5), 2199-2206. doi: 10.4049/jimmunol.1500227

Auray G., Lacroix-Lamande S., Mancassola R., Dimier-Poisson I., and Laurent F. (2007). Involvement of Intestinal Epithelial Cells in Dendritic Cell Recruitment During C. Parvum Infection. Microbes Infect. 9 (5), 574-582. doi: 10.1016/j.micinf.2007.01.026

Barakat F. M., McDonald V., Di Santo J. P., and Korbel D. S. (2009). Roles for NK Cells and an NK Cell-Independent Source of Intestinal Gamma Interferon for 
Innate Immunity to Cryptosporidium Parvum Infection. Infect. Immun. 77 (11), 5044-5049. doi: 10.1128/IAI.00377-09

Barakat F. M., McDonald V., Foster G. R., Tovey M. G., and Korbel D. S. (2009). Cryptosporidium Parvum Infection Rapidly Induces a Protective Innate Immune Response Involving Type I Interferon. J. Infect. Dis. 200 (10), 15481555. doi: $10.1086 / 644601$

Bedi B., McNair N. N., and Mead J. R. (2014). Dendritic Cells Play a Role in Host Susceptibility to Cryptosporidium Parvum Infection. Immunol. Lett. 158 (1-2), 42-51. doi: 10.1016/j.imlet.2013.11.015

Bedi B., and Mead J. R. (2012). Cryptosporidium Parvum Antigens Induce Mouse and Human Dendritic Cells to Generate Th1-enhancing Cytokines. Parasite Immunol. 34 (10), 473-485. doi: 10.1111/j.1365-3024.2012.01382.x

Bhalchandra S., Cardenas D., and Ward H. D. (2018). Recent Breakthroughs and Ongoing Limitations in Cryptosporidium Research. F1000Res 7, 1-9. doi: 10.12688/f1000research.15333.1

Bouzid M., Hunter P. R., Chalmers R. M., and Tyler K. M. (2013). Cryptosporidium Pathogenicity and Virulence. Clin. Microbiol. Rev. 26 (1), 115-134. doi: 10.1128/CMR.00076-12

Carryn S., Schaefer D. A., Imboden M., Homan E. J., Bremel R. D., and Riggs M. W. (2012). Phospholipases and Cationic Peptides Inhibit Cryptosporidium Parvum Sporozoite Infectivity by Parasiticidal and non-Parasiticidal Mechanisms. J. Parasitol 98 (1), 199-204. doi: 10.1645/GE-2822.1

Castellanos-Gonzalez A., Cabada M. M., Nichols J., Gomez G., and White A. C.Jr. (2013). Human Primary Intestinal Epithelial Cells as an Improved In Vitro Model for Cryptosporidium Parvum Infection. Infect. Immun. 81 (6), 19962001. doi: 10.1128/IAI.01131-12

Castellanos-Gonzalez A., Yancey L. S., Wang H. C., Pantenburg B., Liscum K. R., Lewis D. E., et al. (2008). Cryptosporidium Infection of Human Intestinal Epithelial Cells Increases Expression of Osteoprotegerin: A Novel Mechanism for Evasion of Host Defenses. J. Infect. Dis. 197 (6), 916-923. doi: 10.1086/ 528374

Checkley W., Gilman R. H., Epstein L. D., Suarez M., Diaz J. F., Cabrera L., et al. (1997). Asymptomatic and Symptomatic Cryptosporidiosis: Their Acute Effect on Weight Gain in Peruvian Children. Am. J. Epidemiol. 145 (2), 156-163. doi: 10.1093/oxfordjournals.aje.a009086

Chen X. M., Gores G. J., Paya C. V., and LaRusso N. F. (1999). Cryptosporidium Parvum Induces Apoptosis in Biliary Epithelia by a Fas/Fas Ligand-Dependent Mechanism. Am. J. Physiol. 277 (3), G599-G608. doi: 10.1152/ajpgi. 1999.277.3.G599

Chen X. M., O’Hara S. P., Nelson J. B., Splinter P. L., Small A. J., Tietz P. S., et al. (2005). Multiple TLRs are Expressed in Human Cholangiocytes and Mediate Host Epithelial Defense Responses to Cryptosporidium Parvum Via Activation of NFKappab. J. Immunol. 175 (11), 7447-7456. doi: 10.4049/jimmunol.175.11.7447

Chen X. M., Splinter P. L., O'Hara S. P., and LaRusso N. F. (2007). A Cellular micro-RNA, let-7i, Regulates Toll-like Receptor 4 Expression and Contributes to Cholangiocyte Immune Responses Against Cryptosporidium Parvum Infection. J. Biol. Chem. 282 (39), 28929-28938. doi: 10.1074/jbc.M702633200

Chique C., Hynds P. D., Andrade L., Burke L., Morris D., Ryan M. P., et al. (2020). Cryptosporidium Spp. in Groundwater Supplies Intended for Human Consumption - A Descriptive Review of Global Prevalence, Risk Factors and Knowledge Gaps. Water Res. 176:115726. doi: 10.1016/j.watres.2020.115726

Choudhry N., Petry F., van Rooijen N., and McDonald V. (2012). A Protective Role for Interleukin 18 in Interferon Gamma-Mediated Innate Immunity to Cryptosporidium Parvum That is Independent of Natural Killer Cells. J. Infect. Dis. 206 (1), 117-124. doi: 10.1093/infdis/jis300

Corso P. S., Kramer M. H., Blair K. A., Addiss D. G., Davis J. P., and Haddix A. C. (2003). Cost of Illness in the 1993 Waterborne Cryptosporidium Outbreak, Milwaukee, Wisconsin. Emerg. Infect. Dis. 9 (4), 426-431. doi: 10.3201/eid0904. 020417

Dann S. M., Wang H. C., Gambarin K. J., Actor J. K., Robinson P., Lewis D. E., et al. (2005). Interleukin-15 Activates Human Natural Killer Cells to Clear the Intestinal Protozoan Cryptosporidium. J. Infect. Dis. 192 (7), 1294-1302. doi: $10.1086 / 444393$

Dawson D. J., Samuel C. M., Scrannage V., and Atherton C. J. (2004). Survival of Cryptosporidium Species in Environments Relevant to Foods and Beverages. J. Appl. Microbiol. 96 (6), 1222-1229. doi: 10.1111/j.1365-2672.2004.02281.x

DeCicco RePass M. A., Chen Y., Lin Y., Zhou W., Kaplan D. L., and Ward H. D. (2017). Novel Bioengineered Three-Dimensional Human Intestinal Model for
Long-Term Infection of Cryptosporidium Parvum. Infect. Immun. 85 (3), 111. doi: 10.1128/IAI.00731-16

Deng M. Q., and Cliver D. O. (1998). Cryptosporidium Parvum Development in the BS-C-1 Cell Line. J. Parasitol 84 (1), 8-15. doi: 10.2307/3284519

Derricott H., Luu L., Fong W. Y., Hartley C. S., Johnston L. J., Armstrong S. D., et al. (2019). Developing a 3D Intestinal Epithelium Model for Livestock Species. Cell Tissue Res. 375 (2), 409-424. doi: 10.1007/s00441-018-2924-9

de Sablet T., Potiron L., Marquis M., Bussiere F. I., Lacroix-Lamande S., and Laurent F. (2016). Cryptosporidium Parvum Increases Intestinal Permeability Through Interaction With Epithelial Cells and IL-1beta and TNFalpha Released by Inflammatory Monocytes. Cell Microbiol. 18 (12), 1871-1880. doi: $10.1111 / \mathrm{cmi} .12632$

Ehigiator H. N., Romagnoli P., Borgelt K., Fernandez M., McNair N., Secor W. E., et al. (2005). Mucosal Cytokine and Antigen-Specific Responses to Cryptosporidium Parvum in IL-12p40 KO Mice. Parasite Immunol. 27 (1-2), 17-28. doi: 10.1111/j.1365-3024.2005.00736.x

Farache J., Koren I., Milo I., Gurevich I., Kim K. W., Zigmond E., et al. (2013). Luminal Bacteria Recruit CD103+ Dendritic Cells Into the Intestinal Epithelium to Sample Bacterial Antigens for Presentation. Immunity 38 (3), 581-595. doi: 10.1016/j.immuni.2013.01.009

Ferguson S. H., Foster D. M., Sherry B., Magness S. T., Nielsen D. M., and Gookin J. L. (2019). Interferon-Lambda3 Promotes Epithelial Defense and Barrier Function Against Cryptosporidium Parvum Infection. Cell Mol. Gastroenterol. Hepatol 8 (1), 1-20. doi: 10.1016/j.jcmgh.2019.02.007

Gharpure R., Perez A., Miller A. D., Wikswo M. E., Silver R., and Hlavsa M. C. (2019). Cryptosporidiosis Outbreaks - United States, 2009-2017. MMWR Morb Mortal Wkly Rep. 68 (25), 568-572. doi: 10.15585/mmwr.mm6825a3

Giacometti A., Cirioni O., Barchiesi F., Caselli F., and Scalise G. (1999). In-Vitro Activity of Polycationic Peptides Against Cryptosporidium Parvum, Pneumocystis Carinii and Yeast Clinical Isolates. J. Antimicrob. Chemother. 44 (3), 403-406. doi: 10.1093/jac/44.3.403

Goodgame R. W., Kimball K., Ou C. N., White A. C.Jr., Genta R. M., Lifschitz C. H., et al. (1995). Intestinal Function and Injury in Acquired Immunodeficiency Syndrome-Related Cryptosporidiosis. Gastroenterology 108 (4), 1075-1082. doi: 10.1016/0016-5085(95)90205-8

Gormley F. J., Little C. L., Chalmers R. M., Rawal N., and Adak G. K. (2011). Zoonotic Cryptosporidiosis From Petting Farms, England and Wales, 19922009. Emerg. Infect. Dis. 17 (1), 151-152. doi: 10.3201/eid1701.100902

Griffiths J. K., Theodos C., Paris M., and Tzipori S. (1998). The Gamma Interferon Gene Knockout Mouse: A Highly Sensitive Model for Evaluation of Therapeutic Agents Against Cryptosporidium Parvum. J. Clin. Microbiol. 36 (9), 2503-2508. doi: 10.1128/JCM.36.9.2503-2508.1998

Guesdon W., Auray G., Pezier T., Bussiere F. I., Drouet F., Le Vern Y., et al. (2015). Ccl20 Displays Antimicrobial Activity Against Cryptosporidium Parvum, But Its Expression Is Reduced During Infection in the Intestine of Neonatal Mice. J. Infect. Dis. 212 (8), 1332-1340. doi: 10.1093/infdis/jiv206

Guzman E., Price S., Poulsom H., and Hope J. (2012). Bovine Gammadelta T Cells: Cells With Multiple Functions and Important Roles in Immunity. Vet. Immunol. Immunopathol. 148 (1-2), 161-167. doi: 10.1016/ j.vetimm.2011.03.013

Hamilton C. A., Young R., Jayaraman S., Sehgal A., Paxton E., Thomson S., et al. (2018). Development of In Vitro Enteroids Derived From Bovine Small Intestinal Crypts. Vet. Res. 49 (1):54. doi: 10.1186/s13567-018-0547-5

Hashim A., Mulcahy G., Bourke B., and Clyne M. (2006). Interaction of Cryptosporidium Hominis and Cryptosporidium Parvum With Primary Human and Bovine Intestinal Cells. Infect. Immun. 74 (1), 99-107. doi: 10.1128/IAI.74.1.99-107.2006

Hatam-Nahavandi K., Ahmadpour E., Carmena D., Spotin A., Bangoura B., and Xiao L. (2019). Cryptosporidium Infections in Terrestrial Ungulates With Focus on Livestock: A Systematic Review and Meta-Analysis. Parasit Vectors 12 (1), 453. doi: 10.1186/s13071-019-3704-4

Hayward A. R., Chmura K., and Cosyns M. (2000). Interferon-Gamma is Required for Innate Immunity to Cryptosporidium Parvum in Mice. J. Infect. Dis. 182 (3), 1001-1004. doi: 10.1086/315802

Heo I., Dutta D., Schaefer D. A., Iakobachvili N., Artegiani B., Sachs N., et al. (2018). Modelling Cryptosporidium Infection in Human Small Intestinal and Lung Organoids. Nat. Microbiol. 3 (7), 814-823. doi: 10.1038/s41564-0180177-8 
Ivanova D. L., Denton S. L., Fettel K. D., Sondgeroth K. S., Munoz Gutierrez J., Bangoura B., et al. (2019). Innate Lymphoid Cells in Protection, Pathology, and Adaptive Immunity During Apicomplexan Infection. Front. Immunol. 10, 196. doi: 10.3389 /fimmu.2019.00196

Karanis P., and Aldeyarbi H. M. (2011). Evolution of Cryptosporidium In Vitro Culture. Int. J. Parasitol 41 (12), 1231-1242. doi: 10.1016/j.ijpara.2011.08.001

Khalil I. A., Troeger C., Rao P. C., Blacker B. F., Brown A., Brewer T. G., et al. (2018). Morbidity, Mortality, and Long-Term Consequences Associated With Diarrhoea From Cryptosporidium Infection in Children Younger Than 5 Years: A Meta-Analyses Study. Lancet Glob Health 6 (7), e758-e768. doi: 10.1016/S2214-109X(18)30283-3

Kotloff K. L., Nataro J. P., Blackwelder W. C., Nasrin D., Farag T. H., Panchalingam S., et al. (2013). Burden and Aetiology of Diarrhoeal Disease in Infants and Young Children in Developing Countries (the Global Enteric Multicenter Study, GEMS): A Prospective, Case-Control Study. Lancet 382 (9888), 209-222. doi: 10.1016/S0140-6736(13)60844-2

Kumar V. (2019). "Macrophages: The Potent Immunoregulatory Innate Immune Cells," in Macrophage Activation - Biology and Disease. Ed. K. H. Bhat (London, UK: IntechOpen).

Lacroix-Lamande S., Mancassola R., Auray G., Bernardet N., and Laurent F. (2008). CCR5 is Involved in Controlling the Early Stage of Cryptosporidium Parvum Infection in Neonates But is Dispensable for Parasite Elimination. Microbes Infect. 10 (4), 390-395. doi: 10.1016/j.micinf.2007.12.020

Lacroix-Lamande S., Mancassola R., Naciri M., and Laurent F. (2002). Role of Gamma Interferon in Chemokine Expression in the Ileum of Mice and in a Murine Intestinal Epithelial Cell Line After Cryptosporidium Parvum Infection. Infect. Immun. 70 (4), 2090-2099. doi: 10.1128/iai.70.4.2090-2099.2002

Lantier L., Drouet F., Guesdon W., Mancassola R., Metton C., Lo-Man R., et al. (2014). Poly(I:C)-Induced Protection of Neonatal Mice Against Intestinal Cryptosporidium Parvum Infection Requires an Additional TLR5 Signal Provided by the Gut Flora. J. Infect. Dis. 209 (3), 457-467. doi: 10.1093/infdis/jit432

Lantier L., Lacroix-Lamande S., Potiron L., Metton C., Drouet F., Guesdon W., et al. (2013). Intestinal CD103+ Dendritic Cells are Key Players in the Innate Immune Control of Cryptosporidium Parvum Infection in Neonatal Mice. PloS Pathog. 9 (12), e1003801. doi: 10.1371/journal.ppat.1003801

Laurent F., Eckmann L., Savidge T. C., Morgan G., Theodos C., Naciri M., et al. (1997). Cryptosporidium Parvum Infection of Human Intestinal Epithelial Cells Induces the Polarized Secretion of C-X-C Chemokines. Infect. Immun. 65 (12), 5067-5073. doi: 10.1128/IAI.65.12.5067-5073.1997

Laurent F., and Lacroix-Lamande S. (2017). Innate Immune Responses Play a Key Role in Controlling Infection of the Intestinal Epithelium by Cryptosporidium. Int. J. Parasitol 47 (12), 711-721. doi: 10.1016/j.ijpara.2017.08.001

Laurent F., McCole D., Eckmann L., and Kagnoff M. F. (1999). Pathogenesis of Cryptosporidium Parvum Infection. Microbes Infect. 1 (2), 141-148. doi: 10.1016/s1286-4579(99)80005-7

Li X., Chase J. A., Bond R. F., Lor P., Fernandez K., Nguyen T. H., et al. (2019). Microbiological Safety of Popular Recreation Swimming Sites in Central California. Environ. Monit Assess. 191 (7), 456. doi: 10.1007/s10661-019-7601-2

Li M., Gong A. Y., Zhang X. T., Wang Y., Mathy N. W., Martins G. A., et al. (2018). Induction of a Long Noncoding RNA Transcript, NR_045064, Promotes Defense Gene Transcription and Facilitates Intestinal Epithelial Cell Responses Against Cryptosporidium Infection. J. Immunol. 201 (12), 36303640. doi: 10.4049/jimmunol.1800566

Liu J., Deng M., Lancto C. A., Abrahamsen M. S., Rutherford M. S., and Enomoto S. (2009). Biphasic Modulation of Apoptotic Pathways in Cryptosporidium Parvum-Infected Human Intestinal Epithelial Cells. Infect. Immun. 77 (2), 837-849. doi: 10.1128/IAI.00955-08

Mahlapuu M., Hakansson J., Ringstad L., and Bjorn C. (2016). Antimicrobial Peptides: An Emerging Category of Therapeutic Agents. Front. Cell Infect. Microbiol. 6, 194. doi: 10.3389/fcimb.2016.00194

Marcial M. A., and Madara J. L. (1986). Cryptosporidium: Cellular Localization, Structural Analysis of Absorptive Cell-Parasite Membrane-Membrane Interactions in Guinea Pigs, and Suggestion of Protozoan Transport by M Cells. Gastroenterology 90 (3), 583-594. doi: 10.1016/0016-5085(86)91112-1

Marquis N. D., Record N. R., and Robledo J. A. (2015). Survey for Protozoan Parasites in Eastern Oysters (Crassostrea Virginica) From the Gulf of Maine Using PCR-based Assays. Parasitol Int. 64 (5), 299-302. doi: 10.1016/ j.parint.2015.04.001
McCole D. F., Eckmann L., Laurent F., and Kagnoff M. F. (2000). Intestinal Epithelial Cell Apoptosis Following Cryptosporidium Parvum Infection. Infect. Immun. 68 (3), 1710-1713. doi: 10.1128/iai.68.3.1710-1713.2000

McDonald V., Korbel D. S., Barakat F. M., Choudhry N., and Petry F. (2013). Innate Immune Responses Against Cryptosporidium Parvum Infection. Parasite Immunol. 35 (2), 55-64. doi: 10.1111/pim.12020

McDonald V., Pollok R. C., Dhaliwal W., Naik S., Farthing M. J., and Bajaj-Elliott M. (2006). A Potential Role for interleukin-18 in Inhibition of the Development of Cryptosporidium Parvum. Clin. Exp. Immunol. 145 (3), 555-562. doi: 10.1111/j.1365-2249.2006.03159.x

McNair N. N., Bedi C., Shayakhmetov D. M., Arrowood M. J., and Mead J. R. (2018). Inflammasome Components Caspase-1 and Adaptor Protein Apoptosis-Associated Speck-Like Proteins are Important in Resistance to Cryptosporidium Parvum. Microbes Infect. 20 (6), 369-375. doi: 10.1016/ j.micinf.2018.04.006

Mead J. R., Arrowood M. J., Sidwell R. W., and Healey M. C. (1991). Chronic Cryptosporidium Parvum Infections in Congenitally Immunodeficient SCID and Nude Mice. J. Infect. Dis. 163 (6), 1297-1304. doi: 10.1093/infdis/163.6.1297

Mead J. R., and You X. (1998). Susceptibility Differences to Cryptosporidium Parvum Infection in Two Strains of Gamma Interferon Knockout Mice. J. Parasitol 84 (5), 1045-1048. doi: 10.2307/3284643

Mele R., Gomez Morales M. A., Tosini F., and Pozio E. (2004). Cryptosporidium Parvum At Different Developmental Stages Modulates Host Cell Apoptosis In Vitro. Infect. Immun. 72 (10), 6061-6067. doi: 10.1128/IAI.72.10.6061-6067.2004

Miller C. N., Josse L., Brown I., Blakeman B., Povey J., Yiangou L., et al. (2018). A Cell Culture Platform for Cryptosporidium That Enables Long-Term Cultivation and New Tools for the Systematic Investigation of its Biology. Int. J. Parasitol 48 (3-4), 197-201. doi: 10.1016/j.ijpara.2017.10.001

Morada M., Lee S., Gunther-Cummins L., Weiss L. M., Widmer G., Tzipori S., et al. (2016). Continuous Culture of Cryptosporidium Parvum Using Hollow Fiber Technology. Int. J. Parasitol 46 (1), 21-29. doi: 10.1016/j.jpara.2015.07.006

Nag R., Whyte P., Markey B. K., O’Flaherty V., Bolton D., Fenton O., et al. (2020). Ranking Hazards Pertaining to Human Health Concerns From Land Application of Anaerobic Digestate. Sci. Total Environ. 710, 136297. doi: 10.1016/j.scitotenv.2019.136297

Nydam D. V., Wade S. E., Schaaf S. L., and Mohammed H. O. (2001). Number of Cryptosporidium Parvum Oocysts or Giardia Spp Cysts Shed by Dairy Calves After Natural Infection. Am. J. Vet. Res. 62 (10), 1612-1615. doi: 10.2460/ ajvr.2001.62.1612

Odendall C., Voak A. A., and Kagan J. C. (2017). Type III Ifns Are Commonly Induced by Bacteria-Sensing Tlrs and Reinforce Epithelial Barriers During Infection. J. Immunol. 199 (9), 3270-3279. doi: 10.4049/jimmunol.1700250

Olsen L., Akesson C. P., Storset A. K., Lacroix-Lamande S., Boysen P., Metton C., et al. (2015). The Early Intestinal Immune Response in Experimental Neonatal Ovine Cryptosporidiosis is Characterized by an Increased Frequency of Perforin Expressing NCR1(+) NK Cells and by NCR1(-) CD8(+) Cell Recruitment. Vet. Res. 46, 28. doi: 10.1186/s13567-014-0136-1

Ong C. S., Li A. S., Priest J. W., Copes R., Khan M., Fyfe M. W., et al. (2005). Enzyme Immunoassay of Cryptosporidium-specific Immunoglobulin G Antibodies to Assess Longitudinal Infection Trends in Six Communities in British Columbia, Canada. Am. J. Trop. Med. Hyg 73 (2), 288-295. doi: 10.4269/ajtmh.2005.73.288

Perez-Cordon G., Yang G., Zhou B., Nie W., Li S., Shi L., et al. (2014). Interaction of Cryptosporidium Parvum With Mouse Dendritic Cells Leads to Their Activation and Parasite Transportation to Mesenteric Lymph Nodes. Pathog. Dis. 70 (1), 17-27. doi: 10.1111/2049-632X.12078

Petry F., Robinson H. A., and McDonald V. (1995). Murine Infection Model for Maintenance and Amplification of Cryptosporidium Parvum Oocysts. J. Clin. Microbiol. 33 (7), 1922-1924. doi: 10.1128/JCM.33.7.1922-1924.1995

Powell R. H., and Behnke M. S. (2017). WRN Conditioned Media is Sufficient for In Vitro Propagation of Intestinal Organoids From Large Farm and Small Companion Animals. Biol. Open 6 (5), 698-705. doi: 10.1242/bio.021717

Rasmussen K. R., Larsen N. C., and Healey M. C. (1993). Complete Development of Cryptosporidium Parvum in a Human Endometrial Carcinoma Cell Line. Infect. Immun. 61 (4), 1482-1485. doi: 10.1128/IAI.61.4.1482-1485.1993

Rotz L. D., Khan A. S., Lillibridge S. R., Ostroff S. M., and Hughes J. M. (2002). Public Health Assessment of Potential Biological Terrorism Agents. Emerg. Infect. Dis. 8 (2), 225-230. doi: 10.3201/eid0802.010164 
Ryan U., Zahedi A., and Paparini A. (2016). Cryptosporidium in Humans and Animals-a One Health Approach to Prophylaxis. Parasite Immunol. 38 (9), 535-547. doi: 10.1111/pim.12350

Sateriale A., Gullicksrud J. A., Engiles J. B., McLeod B. I., Kugler E. M., HenaoMejia J., et al. (2021). The Intestinal Parasite Cryptosporidium is Controlled by an Enterocyte Intrinsic Inflammasome That Depends on NLRP6. Proc. Natl. Acad. Sci. U.S.A. 118 (2), 1-8. doi: 10.1073/pnas.2007807118

Sateriale A., Slapeta J., Baptista R., Engiles J. B., Gullicksrud J. A., Herbert G. T., et al. (2019). A Genetically Tractable, Natural Mouse Model of Cryptosporidiosis Offers Insights Into Host Protective Immunity. Cell Host Microbe 26 (1), 135-146.e135. doi: 10.1016/j.chom.2019.05.006

Scallan E., Hoekstra R. M., Angulo F. J., Tauxe R. V., Widdowson M. A., Roy S. L., et al. (2011). Foodborne Illness Acquired in the United States-Major Pathogens. Emerg. Infect. Dis. 17 (1), 7-15. doi: 10.3201/eid1701.P11101

Theodos C. M., Sullivan K. L., Griffiths J. K., and Tzipori S. (1997). Profiles of Healing and Nonhealing Cryptosporidium Parvum Infection in C57BL/6 Mice With Functional B and T Lymphocytes: The Extent of Gamma Interferon Modulation Determines the Outcome of Infection. Infect. Immun. 65 (11), 4761-4769. doi: 10.1128/IAI.65.11.4761-4769.1997

Tzipori S. (1998). Cryptosporidiosis: Laboratory Investigations and Chemotherapy. Adv. Parasitol 40, 187-221. doi: 10.1016/s0065-308x(08)60121-9

Upton S. J., Tilley M., and Brillhart D. B. (1994). Comparative Development of Cryptosporidium Parvum (Apicomplexa) in 11 Continuous Host Cell Lines. FEMS Microbiol. Lett. 118 (3), 233-236. doi: 10.1111/j.1574-6968. 1994.tb06833.x

Urban J. F. Jr., Fayer R., Chen S. J., Gause W. C., Gately M. K., and Finkelman F. D. (1996). Il-12 Protects Immunocompetent and Immunodeficient Neonatal Mice Against Infection With Cryptosporidium Parvum. J. Immunol. 156 (1), 263268.

Varughese E. A., Bennett-Stamper C. L., Wymer L. J., and Yadav J. S. (2014). A New In Vitro Model Using Small Intestinal Epithelial Cells to Enhance Infection of Cryptosporidium Parvum. J. Microbiol. Methods 106, 47-54. doi: 10.1016/j.mimet.2014.07.017

Verschoor C. P., Puchta A., and Bowdish D. M. (2012). The Macrophage. Methods Mol. Biol. 844, 139-156. doi: 10.1007/978-1-61779-527-5_10

Yang Z., Fu Y., Gong P., Zheng J., Liu L., Yu Y., et al. (2015). Bovine TLR2 and TLR4 Mediate Cryptosporidium Parvum Recognition in Bovine Intestinal Epithelial Cells. Microb. Pathog. 85, 29-34. doi: 10.1016/j.micpath.2015.05.009
Zaalouk T. K., Bajaj-Elliott M., George J. T., and McDonald V. (2004). Differentia Regulation of Beta-Defensin Gene Expression During Cryptosporidium Parvum Infection. Infect. Immun. 72 (5), 2772-2779. doi: 10.1128/iai.72. 5.2772-2779.2004

Zachos N. C., Kovbasnjuk O., Foulke-Abel J., In J., Blutt S. E., de Jonge H. R., et al. (2016). Human Enteroids/Colonoids and Intestinal Organoids Functionally Recapitulate Normal Intestinal Physiology and Pathophysiology. J. Biol. Chem. 291 (8), 3759-3766. doi: 10.1074/jbc.R114.635995

Zadrozny L. M., Stauffer S. H., Armstrong M. U., Jones S. L., and Gookin J. L. (2006). Neutrophils do Not Mediate the Pathophysiological Sequelae of Cryptosporidium Parvum Infection in Neonatal Piglets. Infect. Immun. 74 (10), 5497-5505. doi: 10.1128/IAI.00153-06

Zambriski J. A., Nydam D. V., Wilcox Z. J., Bowman D. D., Mohammed H. O., and Liotta J. L. (2013). Cryptosporidium Parvum: Determination of $\operatorname{ID(5)(0)}$ and the Dose-Response Relationship in Experimentally Challenged Dairy Calves. Vet. Parasitol 197 (1-2), 104-112. doi: 10.1016/j.vetpar.2013.04.022

Zhang X. T., Gong A. Y., Wang Y., Chen X., Lim S. S., Dolata C. E., et al. (2016). Cryptosporidium Parvum Infection Attenuates the Ex Vivo Propagation of Murine Intestinal Enteroids. Physiol. Rep. 4 (24), 1-13. doi: 10.14814/ phy2.13060

Zhou J. H., Wang Y. N., Chang Q. Y., Ma P., Hu Y., and Cao X. (2018). Type III Interferons in Viral Infection and Antiviral Immunity. Cell Physiol. Biochem. 51 (1), 173-185. doi: 10.1159/000495172

Ziegler P. E., Wade S. E., Schaaf S. L., Stern D. A., Nadareski C. A., and Mohammed H. O. (2007). Prevalence of Cryptosporidium Species in Wildlife Populations Within a Watershed Landscape in Southeastern New York State. Vet. Parasitol 147 (1-2), 176-184. doi: 10.1016/j.vetpar.2007.03.024

Conflict of Interest: The authors declare that the research was conducted in the absence of any commercial or financial relationships that could be construed as a potential conflict of interest.

Copyright (C) 2021 Crawford and Kol. This is an open-access article distributed under the terms of the Creative Commons Attribution License (CC BY). The use, distribution or reproduction in other forums is permitted, provided the original author(s) and the copyright owner(s) are credited and that the original publication in this journal is cited, in accordance with accepted academic practice. No use, distribution or reproduction is permitted which does not comply with these terms. 